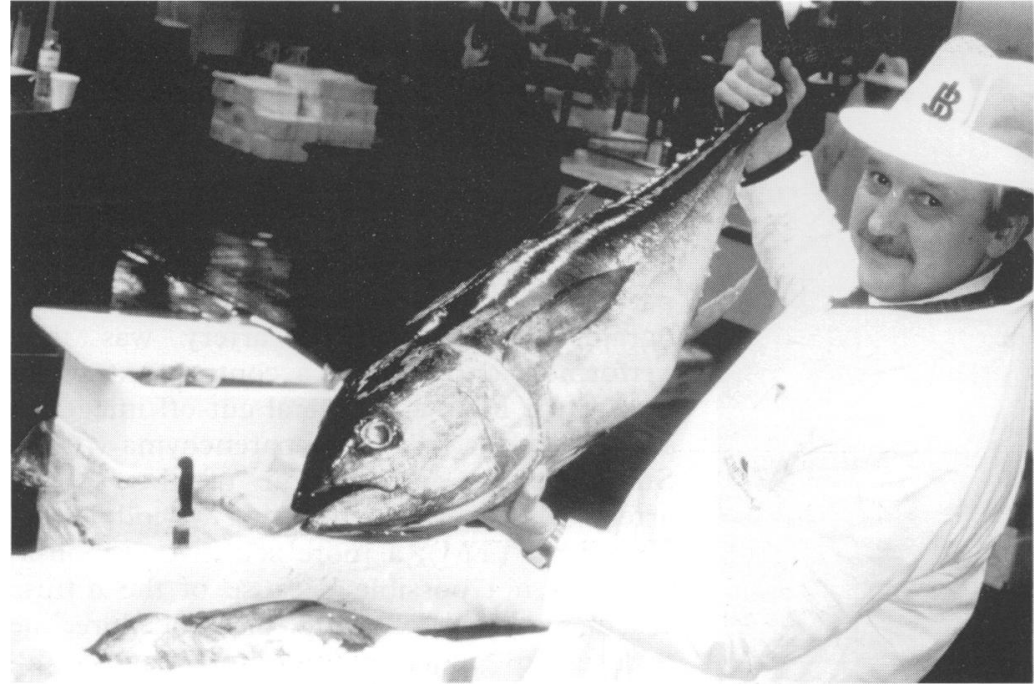

Tuna fish, a member of the scombroid family.

canned fish, poor handling from catching to canning is more usually the problem. ${ }^{4}$

Symptoms may begin in the mouth almost immediately, with numbness, tingling, or burning. This may be followed within minutes to a few hours by headache, a red rash over the face, neck and upper trunk, nausea, and diarrhoea. Complete recovery within 12 hours is usual. Antihistamines lead to a rapid resolution of symptoms: $\mathrm{H}_{1}$ receptor antagonists such as chlorpheniramine are effective, but $\mathrm{H}_{2}$ receptor antagonists such as cimetidine may be better. ${ }^{5}$

The exact mechanism whereby histamine reaches the circulation in scombrotoxin poisoning is not known as pure histamine given by mouth is rapidly metabolised by gut enzymes. If, as is usually assumed, the histamine in the fish is responsible for the symptoms, then some other factor must inhibit its metabolism in the gut, perhaps other amines. Another suggested mechanism is that some other toxin in the fish is absorbed from the gut and causes endogenous histamine release, perhaps from basophils.

Cases of scombrotoxin poisoning have been reported throughout the world, but are commonest in the United Kingdom, the USA, and Japan.

\section{CONCLUSION}

Scombrotoxin poisoning should be considered in any patient who suffers the typical symptoms after eating fish. It may be that many episodes are ascribed to food sensitivity, and the reported numbers may not reflect the true incidence of this condition.

I thank Dr $\mathbf{P}$ Towsland, retired consultant in chemical pathology, Guy's Hospital, for performing the histamine analysis on the first case; and Dr Ann Scoging of the Food Hygiene Laboratory, Central Public Health Laboratory, for helpful information and for arranging the histamine analyses on the information

1 Scoging AC. Illness associated with seafood. Commun Dis Rep 1991;1:R117-22.

2 Taylor SL. Histamine food poisoning: toxicology and clinical aspects. CRC Crit Rev Toxicol 1986;17:91-128.

3 Clifford MN, Walker R, Ijomah P, Wright J, Murray CK, Hardy $R$. Is there a role for amines other than histamines in the aetiology of scombrotoxicosis? Food Addit Contam $1991 ; 8: 641-52$.

4 Merson MH, Baine WB, Gangarosa EJ, Swanson RC. Scombroid fish poisoning - outbreak traced to commercially canned tuna fish. JAMA $1974 ; 228: 1268-9$.

5 Blakesley ML. Scombroid poisoning: prompt resolution of symptoms with cimetidine. Ann Emerg Med 1983;12: 104-6.

\title{
Non-operative management of a splenic laceration in a patient with the Proteus syndrome
}

\author{
W Ceelen, J De Waele, M Kunnen, B de Hemptinne
}

University Hospital,

Gent University

Medical School, De

Pintelaan 185, B-9000

Gent, Belgium:

Department of

Surgery

W Ceelen

J De Waele

B de Hemptinne

Department of

Radiology

M Kunnen

Correspondence to:

Wim P Ceelen.

Accepted for publication 17 July 1996

\begin{abstract}
An adult patient with the Proteus syndrome sustained a grade III splenic laceration after falling off a horse. Clinical features of this rare disorder include subcutaneous and visceral hamartomatous tumours. The patient also suffered from chronic intravascular coagulation associated with extensive haemangiomatosis (Kasabach-Merritt syndrome). Considering the visceral anomalies and abnormal coagulation, a non-operative approach was preferred despite considerable transfusion requirement, and the patient successfully underwent embolisation of the splenic artery. This is the first reported case of splenic injury in a patient with Proteus syndrome.

(F Accid Emerg Med 1997;14:111-113)
\end{abstract}

Keywords: splenic injury; embolisation; KasabachMerritt syndrome; Proteus syndrome.
The spleen is the most frequently injured intra-abdominal organ following blunt abdominal trauma. In recent years, a less aggressive approach toward splenic laceration is accepted as being as safe as urgent splenectomy in selected cases. Attempts have been made to identify and test criteria for safe non-surgical management of splenic injuries. We present an adult patient with the Proteus syndrome and associated coagulation abnormalities due to large subcutaneous hamartomas (Kasabach-Merritt syndrome) who sustained a laceration of the spleen following blunt injury.

\section{Case report}

A 23 year old male patient with the Proteus syndrome since childhood fell of a horse. $\mathrm{He}$ did not immediately seek medical attention. The morning after, however, he woke up with severe upper abdominal pain and fainting, and was admitted to the emergency department. 


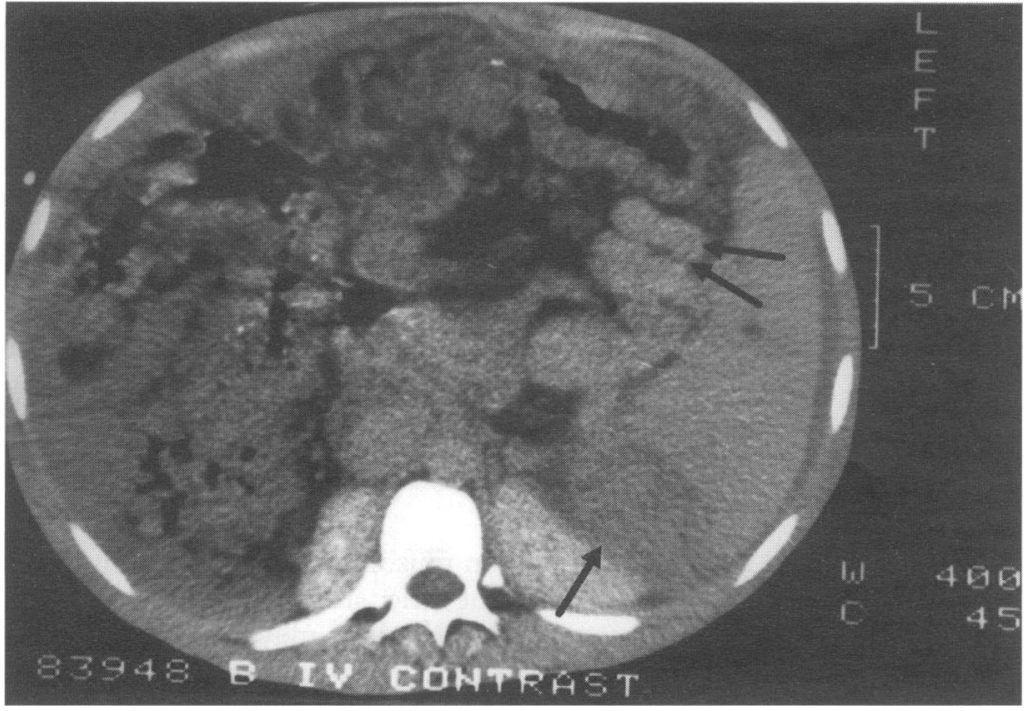

Figure 1 Abdominal CT scan showing grade III laceration at the lower pole of the spleen (arrow). As part of the Proteus syndrome, the patient had multiple intra-abdominal hamartomas (double arrow).

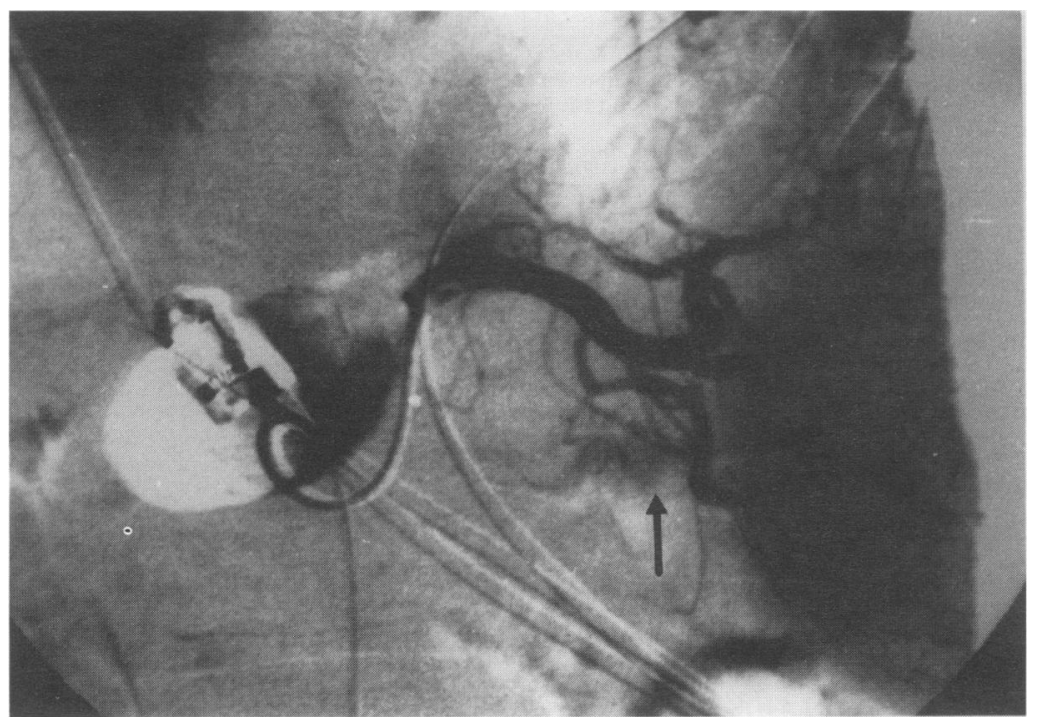

Figure 2 Digital subtraction angiography of the splenic artery, showing contrast extravasation at the hilus (arrow) and several cut-off images in the parenchyma.

On admission, blood pressure was $115 / 65$ $\mathrm{mm} \mathrm{Hg}$ and pulse rate was 76 beats/min. The manifestations of the Proteus syndrome in this patient included exostoses of the facial bones, diffuse subcutaneous and intra-abdominal hamartomas, and macrodactyly of both feet. The patient looked anaemic. Clinical examination revealed hepatosplenomegaly; there was severe pain on palpation of the left and right upper abdomen. There was no rebound tenderness or guarding.

Laboratory analyses revealed a haemoglobin level of $14.2 \mathrm{~g} / \mathrm{dl}$, abnormally low fibrinogen $(118 \mathrm{mg} / \mathrm{dl})$ and prothrombin time $(47 \%)$, and raised indirect bilirubin $(2.45 \mathrm{mg} / \mathrm{dl})$ and lactate dehydrogenase (510 U/litre). The patient was known to have a chronic intravascular haemolysis.

Ultrasound of the abdomen revealed a large, irregular liver; the spleen was also enlarged and contained a hyporeflective zone of $4 \mathrm{~cm}$ diameter at the lower pole; intraperitoneal fluid was also noted. A computerised tomography (CT) scan of the abdomen showed an AAST grade III splenic injury at the lower pole and haemoperitoneum (fig 1). A nonoperative approach was preferred and the patient was admitted to the ICU. Initially, the packed cell volume remained stable around $30 \%$. After 24 hours, however, it suddenly fell to $20 \%$ and did not increase despite a massive transfusion of packed red cells and fresh frozen plasma. Angiography of the splenic artery was then performed, and showed a contrast extravasation at the hilus and several cut-off images of smaller vessels inside the parenchyma (fig 2). Subsequently, embolisation of the splenic artery was performed using lipiodol and Histoacryl (TM); a more selective embolisation was not possible because of the diffuse vascular injury. Following this procedure, the transfusion requirement immediately decreased; the patient's condition gradually improved and he was ultimately able to leave the hospital 10 days after admission.

\section{Discussion}

The Proteus syndrome is a congenital hamartomatous disorder characterised by partial gigantism, macrodactyly, subcutaneous tumours, and exostoses of the skull bones. The condition has a varying phenotype, and was named after the ancient Greek god Proteus, who could take various shapes to mislead enemies. First described by Wiedemann in 1983, approximately 60 cases have been described up to now. ${ }^{12}$

It is now generally accepted that Joseph Merrick, the famous Elephant Man, probably suffered from Proteus syndrome. ${ }^{3}$ Most cases are sporadic; in only two cases has transmission of the disease been suspected. ${ }^{45} \mathrm{~A}$ somatic mutation model has therefore been proposed, and there appears to be disturbed production of growth factors and growth factor binding proteins in the affected tissues. ${ }^{6}$

The presence of vascular tumours is one of the more constant features of Proteus syndrome; most of these tumours have been shown to be lymphatic hamartomas by immunohistological staining. ${ }^{7}$ The patient we describe suffered from extensive hamartomas of the abdominal wall; he was also known to have widespread hamartomata in the abdominal viscera. Moreover, the extent of vascular malformation in this patient gave rise to a chronic consumption coagulopathy, known as the Kasabach-Merritt syndrome.

Non-operative management of splenic lacerations remains a matter of debate in trauma surgery. Some clinicians have advocated conservative treatment and have attempted to define criteria identifying patients in whom observation is the only necessary treatment. These criteria include haemodynamic stability, age of less than 55 years, absence of or minimal peritoneal signs, CT scan injury grade less than III (AAST), and absence of injury to other intra-abdominal organs..$^{8-12}$

Others advise early laparotomy in order to maximise splenic salvage, rather than removing the spleen after failure of non-surgical treatment, 
which is reported to occur in as many as $70 \%$ of cases. ${ }^{1314}$

Our patient was managed conservatively because of his haemodynamic stability and minimal peritoneal signs. When his condition gradually worsened, a laparotomy was considered too hazardous because of the coagulation disorder and the multiple intra-abdominal hamartomas. Urgent angiography was performed, and embolisation of the splenic artery was possible, completely controlling the haemorrhage.

Arterial embolisation is not routinely used in controlling intra-abdominal bleeding following trauma. A few reports mention its use in treating bleeding from post-traumatic pseudoaneurysms ${ }^{15}$ or splenic trauma in a patient with hepatic cirrhosis. ${ }^{13}$ Only one report mentions its limited role in patients who are a poor operative risk. ${ }^{16}$

This case illustrates the possible role of therapeutic angiography in the management of splenic trauma in the presence of major drawbacks to surgery.

1 Wiedemann HR, Burgio GR, Aldenhoff P, et al. The proteus syndrome. Partial gigantism of the hands and/or feet, nevi, hemihypertrophy, subcutaneous tumors, macrocephaly or other skull anomalies and possible accelerated growth and visceral affections. Eur J Pediatr 1983;140:5-12.

2 Vaughn RY, Selinger AD, Howell CG, et al. Proteus syndrome: diagnosis and surgical management. J Pediatr Surg $1993 ; 28: 5-10$
3 Tibbles JA, Cohen MM. The Proteus syndrome: the Elephant Man diagnosed. BMJ 1986;293:683-5.

4 Kruger G, Pelz L, Wiedemann HR. Transmission of Proteus syndrome from mother to son? Am J Med Genet 1993;45: $117-8$.

5 Goodship J, Redfearn A, Milligan D, et al. Transmission of Proteus syndrome from father to son? J Med Genet 1991; 28:781-5.

6 Rudolph G, Blum WF, Jenne EW, et al. Growth hormone (GH), insulin-like growth factors (IGFs), and IGF-binding protein-3 (IGFBP-3) in a child with Proteus syndrome. Am J Med Genet 1994;50:204-10.

7 Vaughn RY, Lesher JL, Chandler FW, et al. Histogenesis of vascular tumors in the Proteus syndrome. South Med J 1994;87:228-82.

8 Mucha P, Daly RC, Farnell MB. Selective management of blunt splenic trauma. J Trauma 1986;26:970-9.

9 Smith JS, Wengrovitz MA, DeLong BS. Prospective validation of criteria, including age, for safe nonsurgical managetion of criteria, including age, for safe nonsurgical mana

10 Kohn JS, Clark DE, Isler RJ, et al. Is computed tomographic grading of splenic injury useful in the nonsurgical managment of blunt trauma? J Trauma 1994;36:385-9.

11 Cogbill TH, Moore EE, Jurkovich GJ, et al. Nonoperative management of blunt splenic trauma: a multicenter experience. J Trauma 1989;29:1312-7.

12 Longo WE, Baker CC, McMillen MA, et al. Nonoperative management of adult blunt splenic trauma. Ann Surg $1989 ; 210: 626-9$

13 Nallathambi MN, Ivatury RR, Wapnir I, et al. Nonoperative management versus early operation for blunt splenic trauma in adults. Surg Gynecol Obstet 1988;166:252-8.

14 Rappaport W, McIntyre KE, Carmona R. The managemen of splenic trauma in the adult patient with blunt multiple iniuries. Surg Gynecol Obstet 1990;170:204-8.

$15 \mathrm{Kahn}$ AB, Reid AW. Management of renal stab wounds by arteriographic embolization. Scand J Urol Nephrol 1994 28:109-10.

16 Scalfani SJ, Shaftan GW, Phillip TF, et al. Percutaneous transcatheter arterial embolization. J Trauma $1985 ; 25$ 1021-9.

\title{
An unusual cause of rib fracture following a road traffic accident
}

\author{
R J Daniels, R A Fulcher
}

\begin{abstract}
A case is presented which is thought to be the first described example of rib fracture occurring as a result of airbag inflation. It would appear that the propellant cartridge came loose during deployment to form a missile, striking the patient on his chest and fracturing a rib.

( 7 Accid Emerg Med 1997;14:113-114)
\end{abstract}

Royal Devon and Exeter Hospital,

Barrack Road, Exeter

EX2 5DW, United

Kingdom

R J Daniels

Department of

Medicine for the

Elderly, Norfolk and

Norwich Hospital,

Brunswick Road,

Norwich NR1 3SR,

United Kingdom

R A Fulcher

Correspondence to:

Dr R J Daniels, 9 Mile End

Road, Norwich NR4 7QY.

Accepted for publication 18 September 1996
Keywords: airbag; airbag related injury; rib fracture.

\section{Case report}

The patient, a 73 year old asthmatic, was driving a 1994 Ford Mondeo 1.8 LX estate when he was involved in a low velocity frontal collision with another vehicle. The patient was wearing a seatbelt and the impact caused his air bag to inflate. Immediately after the impact, the patient felt a sharp blow on the left side of his chest. He received no other injuries. He was admitted to hospital complaining of chest pain, shortness of breath, and difficulty in breathing.

Examination of his chest revealed reduced expansion bilaterally, basal crepitations, and focal tenderness over his left anterolateral chest wall. Breath sounds were vesicular and no wheeze was heard. The jugular venous pulse was not raised and the trachea was central. Peak expiratory flow rate was 180 litres $/ \mathrm{min}$, compared with a normal value of 300 litres/ min for this patient. An ECG showed no acute ischaemic changes and arterial blood gases on air were normal. A chest $x$ ray was taken of the patient which showed a fracture of the left ninth rib laterally (fig 1). The patient was treated with analgesia, and admitted overnight for observation. He made an uneventful recovery and was discharged the following day.

Close examination of the clothes that this patient was wearing at the time of the crash revealed a hole approximately $1.5 \mathrm{~cm}$ in diameter surrounded by a chemical residue in a position overlying the site of the fracture (figs 2 and 3). Unfortunately it was not possible for chemical analysis to be performed on this residue. The patient reported that the coat was undamaged before the accident.

\section{Discussion}

Many studies have shown the benefits of airbags as a passenger restraint system, particularly in conjunction with seatbelts, where their use has been estimated to reduce fatalities by 